\title{
Caspase Inhibitor Infusion Protects an Avian Song Control Circuit from Seasonal-Like Neurodegeneration
}

\author{
Christopher K. Thompson ${ }^{1}$ and Eliot A. Brenowitz ${ }^{1,2}$ \\ ${ }^{1}$ Graduate Program in Neurobiology and Behavior and ${ }^{2}$ Departments of Psychology and Biology, University of Washington, Seattle, Washington 98195- \\ 1525
}

Sex steroids such as androgens and estrogens have trophic effects on the brain and can ameliorate neurodegeneration, and the withdrawal of circulating steroids induces neurodegeneration in several hormone-sensitive brain areas. Very little is known about the underlying molecular mechanisms that mediate neuronal regression caused by hormone-withdrawal, however. Here we show that reduction of programmed cell death by local infusion of caspase inhibitors rescues a telencephalic nucleus in the adult avian song control system from neurodegeneration that is induced by hormone withdrawal. This treatment also has trans-synaptic effects that provide some protection of an efferent target region. We found that unilateral infusion of caspase inhibitors in vivo in adult white-crowned sparrows rescued neurons within the hormone-sensitive song nucleus HVC (used as a proper name) from programmed cell death for as long as seven days after withdrawal of testosterone and a shift to short-day photoperiod and that the activation of caspase- 3 was reduced by $59 \%$ on average in the ipsilateral HVC compared with the unmanipulated contralateral HVC. Caspase inhibitor infusion near HVC was sufficient to preserve neuron size ipsilaterally in a downstream nucleus, the robust nucleus of the arcopallium. This is the first report that sustained local application of caspase inhibitors can protect a telencephalic brain area from neurodegeneration in vivo and that a degenerating neural circuit rescued with caspase inhibitors produces sufficient trophic support to protect attributes of a downstream target that would otherwise degenerate. These results strengthen the case for the possible therapeutic use of caspase inhibitors under certain neurodegenerative conditions.

Key words: apoptosis; birdsong; caspase; neuroendocrine; neuroethology; neuroprotection; plasticity; testosterone

\section{Introduction}

Sex steroids such as testosterone (T) provide trophic support to hormone-sensitive brain structures in adult animals. The supportive role played by $\mathrm{T}$ is best demonstrated by withdrawal of hormones after castration, which leads to regression of various neuronal attributes in several brain areas across several vertebrate taxa (Breedlove and Arnold, 1981; Commins and Yahr, 1984; Panzica et al., 1987; Wade et al., 1993; Iela et al., 1994; Soma et al., 1996; Cooke et al., 1999). Furthermore, T and its metabolites $17-\beta$ estradiol $\left(\mathrm{E}_{2}\right)$ and $5-\alpha$ dihydrotestosterone (DHT) can protect neurons under various neurodegenerative conditions (Garcia-Segura et al., 2001; Veiga et al., 2004). Indeed, declines of circulating levels of $\mathrm{T}$ in aging men are implicated in accelerating cognitive decline and exacerbating neurodegenerative disorders (Veiga et al., 2004). However, despite the occurrence of this phenomenon across taxa and its clinical relevance to aging men, little is known about the underlying molecular mechanisms that mediate neurodegeneration caused by the withdrawal of circulating $\mathrm{T}$.

Received Feb. 13, 2008; revised May 19, 2008; accepted May 28, 2008.

This work was supported by National Institutes of Health Grants MH53032, P30DC04661, DC03829, T32DC05361, and 5 T32-GM07108. We thank E. Rubel, K. Lent, and P. Berberian for technical assistance.

Correspondence should be addressed to Christopher K. Thompson, University of Washington, Box 351525, Seattle, WA 98195-1525. E-mail: ckthomps@u.washington.edu.

DOI:10.1523/JNEUROSCI.0663-08.2008

Copyright $\odot 2008$ Society for Neuroscience $\quad$ 0270-6474/08/287130-07\$15.00/0
Song behavior in oscine passerines is regulated by a series of discrete brain nuclei known as the song control system (see Fig. $1 A)$. This brain circuit serves as an excellent model for understanding hormone-dependent neurodegeneration because many nuclei normally undergo substantial seasonal changes that are related to the reproductive status of the animal, especially circulating levels of T. Seasonal-like regression in the song control system stands out among other models of hormone-mediated brain plasticity because these changes are rapid and robust (Thompson et al., 2007). When circulating $\mathrm{T}$ is rapidly withdrawn from breeding-condition adult male white-crowned sparrows (Zonotrichia leucophrys), HVC (used as a proper name) volume regresses quickly, initially driven by an increase in neuronal density within $12 \mathrm{~h}$, followed by a $26 \%$ decrease in neuron number 2-4 d later. The volumes of robust nucleus of the arcopallium (RA) and Area X, efferent nuclei of HVC, regress more slowly over days to weeks and result primarily from changes in neuronal size and density but not neuron number (Thompson and Brenowitz, 2005; Thompson et al., 2007).

Seasonal growth of RA and Area X is dependent on transsynaptic afferent input from HVC. Unilateral lesion of HVC blocks the growth of ipsilateral RA and Area X in response to systemic administration of $\mathrm{T}$ and exposure to long-day photoperiod (LD) (Brenowitz and Lent, 2001). In addition, an intracerebral T implant placed near HVC in nonbreeding male whitecrowned sparrows induces the growth of the ipsilateral HVC, RA, 
and Area X (Brenowitz and Lent, 2002). This transsynaptic influence is driven by the action of T in HVC; a T implant placed near RA does not promote the growth of ipsilateral song control nuclei. Infusion of DHT and $\mathrm{E}_{2}$ near HVC in male birds under short-day photoperiod (SD) is sufficient to induce growth of ipsilateral RA soma area; infusion near RA has no effect (Meitzen et al., 2007).

Although little is known about the molecular mechanisms that underlie neuronal regression caused by $\mathrm{T}$ withdrawal, degeneration of brain circuits typically involves the activation of programmed cell death pathways (Mattson, 2000; Okouchi et al., 2007). In particular, caspases are a family of proteases that play an integral role in programmed cell death pathways in vertebrates and invertebrates (Kumar, 2006). The use of inhibitors that reduce the activity of various caspases have elucidated the role of caspase-dependent programmed cell death and may have clinical significance (Ray, 2006). Here we block caspase activation by infusing a mixture of caspase inhibitors near HVC on one side of the brain in vivo to protect the ipsilateral song control system circuit from degeneration.

\section{Materials and Methods}

All procedures followed National Institutes of Health animal use guidelines and were approved by the University of Washington Institutional Animal Care and Use Committee. We captured 15 male Gambel's whitecrowned sparrows (Zonotrichia leucophrys Gambelii) in eastern Washington during their postbreeding season migration. We housed the birds in indoor group aviaries for at least 12 weeks on SD ( $8 \mathrm{~h}$ light) before the start of the experiment to ensure that the song system and reproductive system were fully regressed and sensitive to the stimulatory effects of $\mathrm{T}$ and long-day photoperiods.

The song system nuclei in wild male white-crowned sparrows increase in size in response to a gradual increase in circulating $\mathrm{T}$ levels as day length increases and the testes grow. The timing of the increase in circulating $\mathrm{T}$ levels varies across individuals, however. To reduce individual variability, we exposed all birds to the same long-day photoperiod and administered $\mathrm{T}$ subcutaneously to rapidly elevate plasma $\mathrm{T}$ concentrations to those seen in breeding birds $(4-12 \mathrm{ng} / \mathrm{ml}$ ) (Wingfield and Farner, 1978). Although this transition occurs more gradually in the wild, this laboratory manipulation recreates the two most important seasonal influences on white-crowned sparrows: elevated T levels and a long-day photoperiod typical of their Alaskan breeding grounds $(20 \mathrm{~h}$ of light per day). It offers the advantage of providing a discrete starting point for time course studies of growth and regression of song circuits.

At the beginning of the experiment, we transferred the birds from an $8 / 16 \mathrm{~h}$ light/dark cycle (SD) to 20/4 h light/dark cycle (LD) overnight (Fig. $1 B$ ). The next day, we anesthetized each bird with isoflurane through a non-rebreathing system and castrated them. We made a small incision on the left side anterior to the caudalmost rib and dorsal to the uncinate process and aspirated both testes. Once castrated, we implanted each bird subcutaneously with a $12 \mathrm{~mm}$ SILASTIC capsule (inner diameter $\times$ outer diameter, $1.47 \times 1.96 \mathrm{~mm}$ ) filled with crystalline $\mathrm{T}$ (Steraloids). We castrated the birds at the onset of LD to avoid subjecting birds to this additional surgery when they were later implanted with intracerebral cannulas at the transition from breeding to nonbreeding conditions. We housed the birds individually in visual and auditory contact with the other birds used in this experiment. We kept all the birds on long-day photoperiod and high levels of circulating T ( LD + T) for $28 \mathrm{~d}$. This time period is sufficient to induce full growth of the song control system under these conditions (Tramontin et al., 2000).

After $26 \mathrm{~d}$ of $\mathrm{LD}+\mathrm{T}$ conditions, we implanted a cannula attached to an osmotic pump unilaterally near HVC in each bird. We anesthetized each bird with isoflurane and placed it into a stereotaxic head holder. We made an incision into the scalp, removed the portion of the skull overlying the midsagittal sinus, and used the bifurcation of the midsagittal sinus as the zero point. We randomly chose a hemisphere and lowered the cannula $0.75 \mathrm{~mm}$ into the telencephalon just caudal to HVC (lateral, $2.8 \mathrm{~mm}$; posterior, $0.4 \mathrm{~mm}$ ). We fixed the cannula to the skull with dental cement and attached an osmotic pump (Alzet) to the cannula. Twelve birds received osmotic pumps filled with a mixture of caspase inhibitors ( $0.015 \mathrm{mg}$ in $100 \mu \mathrm{l}$ in $1 \%$ DMSO in equal concentrations: pan-caspase inhibitor (Z-VAD-FMK; R\&D Systems), caspase-3 inhibitor (Z-DEVDFMK; Calbiochem), and caspase-9 inhibitor (Z-LEHD-FMK; Calbiochem). Three birds received osmotic pumps filled with Z-FA-FMK (Calbiochem), a negative control for caspase inhibitors ( $0.015 \mathrm{mg}$ in $100 \mu \mathrm{l}$ in $1 \%$ DMSO) (Ekdahl et al., 2001). We placed the osmotic pumps into microcentrifuge tubes filled with avian saline $(0.9 \% \mathrm{NaCl})$, sealed the tubes with paraffin and quick-drying cement, and mounted the tubes into "backpacks" custom made for white crowned sparrows. The osmotic pump rested between the bird's wings and allowed for free movement. Osmotic pumps released their contents similarly to those implanted subcutaneously, and the backpack system reduced the risks of secondary infection, extrusion of pumps, and mortality that can occur with subcutaneous implant.

We removed the subcutaneous T capsule $2 \mathrm{~d}$ after the cannula implantation to ensure the onset of infusion of caspase inhibitors (or negative control) into HVC before T withdrawal. We shifted the birds overnight to a $14 / 10 \mathrm{~h}$ light/dark cycle the same day as the $\mathrm{T}$ withdrawal and the next day shifted them overnight to SD. The intermediate photoperiod helped birds adjust to the reduction in available feeding time. We killed groups 
of birds $1 \mathrm{~d}(n=3), 3 \mathrm{~d}(n=4)$, and $7 \mathrm{~d}$ (caspase inhibitor mixture, $n=$ 5; negative control, $n=3$ ) after T withdrawal, which we consider as the onset of nonbreeding conditions.

Blood draw and hormone analysis. We took blood samples from the birds at various time points throughout the experiment to measure circulating T levels. We withdrew $250 \mu \mathrm{l}$ of blood from the alar vein in the wing into heparinized collection tubes. We immediately centrifuged the tubes to separate the plasma, which was stored at $-20^{\circ} \mathrm{C}$ until assay. We measured plasma $\mathrm{T}$ concentration using the Coat-A-Count Total Teststerone radioimmunoassay kit (Diagnostic Products). The minimum detectable plasma T concentration was $0.09 \mathrm{ng} / \mathrm{ml}$. Samples with undetectable levels of steroid were treated as having concentrations at this detection limit for statistical analysis.

Perfusion and tissue processing. We deeply anesthetized the birds with isoflurane inhalation and perfused them through the heart with heparinized saline, followed by $4 \%$ phosphate-buffered paraformaldehyde ( $\mathrm{pH}$ 7.4). We postfixed the brains in $4 \%$ paraformaldehyde for $24 \mathrm{~h}$, embedded the brains in gelatin, and postfixed the gelatin-embedded brains in a $20 \%$ sucrose-neutral buffered Formalin solution for $48 \mathrm{~h}$. We sectioned the brains in the coronal plane at $40 \mu \mathrm{m}$ on a freezing microtome, mounted every third section, and stained with thionin. We kept alternate sections in saline $(0.7 \%)$ for immunohistochemistry (see below).

Measurement of nuclei volume. Using an overhead projector, we traced the borders in both hemispheres throughout the full rostrocaudal extent of HVC, RA, and Area X. We scanned these tracings into a microcomputer and measured the surface area of each cross section using a customized module of NIH Image. We determined the volumes of nuclei by summing the estimated volume between sections calculated with the formula for the volume of a cone frustum (Tramontin et al., 1998).

Measurement of neuronal attributes in HVC and RA. We sampled neuron size by measuring the cross-sectional area of the soma in every mounted section throughout the rostrocaudal axis of HVC and RA. We distinguished neurons from glia by their single nucleolus and uniform, nongranular cytoplasm. We used a random, systematic sampling protocol that has been previously described and validated (Tramontin et al., 1998), which yields estimates of neuronal density and size that do not differ from those obtained using the stereological optical dissector method. We measured the somatic area of at least 150 HVC neurons and 100 RA neurons per hemisphere of each bird in fields chosen randomly by computer in each section. In thin sections, there is a likelihood of splitting of neuronal nuclei between sections, which could overestimate cell counts (West, 1993; Coggeshall and Lekan, 1996). To estimate neuron density, we therefore counted neuronal nucleoli in every field and used Konigsmark's (Nauta and Ebbesson, 1970) formula 4 to correct for nucleus splitting: $N / n=t /\left(t+2\left(\operatorname{sqrt}\left(r^{2}-(k / 2)^{2}\right)\right)\right.$, where $N$ is the number of nucleoli present, $n$ is the number of nucleoli counted, $t$ is the section thickness in micrometers, $r$ is the nucleolus radius, and $k$ is the diameter of the uncounted fragments of nucleoli. We set $k$ equal to $1 \mu \mathrm{m}$, which equaled the smallest nucleolus fragment encountered in this study. Konigsmark-corrected neuron counts were divided by the volume of the tissue sampled to obtain neuronal density.

We estimated neuron number by multiplying neuron density by total nucleus volume. We sampled at least 150 HVC neurons and 100 RA neurons throughout the rostrocaudal extent of each nucleus in each brain. This sample size is sufficient to encompass the entire range of variability in neuron density and somatic area in these nuclei, based on Tramontin et al. (1998). All measurements were made blind to the time of death for each bird.

Caspase-3 immunohistochemistry. To determine whether caspase inhibitor infusion sufficiently decreased caspase activation, we performed immunohistochemistry for activated caspase-3, a protease that mediates programmed cell death. We rinsed floating sections containing contralateral and ipsilateral HVC in three washes of $0.1 \mathrm{~m}$ PBS with $0.1 \%$ Triton X-100 (PBS-TX), $\mathrm{pH} 7.4$, and transferred them to $90-95^{\circ} \mathrm{C}, 10$ mM sodium citrate ( $\mathrm{pH} \mathrm{6.0)}$ ) for $20 \mathrm{~min}$. We allowed the sections to cool to room temperature for $20 \mathrm{~min}$, rinsed them in PBS-TX three times, preblocked the tissue in $10 \%$ normal goat serum for $1 \mathrm{~h}$, and incubated the tissue with a primary antibody against the activated form of caspase- 3 (1:1000 in $10 \%$ NGS; Abcam) overnight at $4^{\circ} \mathrm{C}$. We washed the sections in three washes of PBS-TX, blocked endogenous peroxidase activity with 10 min of $3 \% \mathrm{H}_{2} \mathrm{O}_{2}$ in $10 \% \mathrm{MeOH}$ and $0.1 \mathrm{M}$ PBS, washed the sections in three washes of PBS-TX, and incubated the sections for $45 \mathrm{~min}$ in $0.01 \mathrm{M}$ PBS containing the secondary antibody (1:200). We visualized with avidin-biotin amplification (Vectastain Elite; Vector Laboratories) and diaminobenzidine chromagen. Negative control tissue was prepared by omitting either the primary or the secondary antibody. These sections showed no staining of cells or neuropil. We mounted the sections onto gelatin-subbed slides, let them air dry overnight, and coverslipped the slides with DPX mountant.

To quantify the activation of caspase- 3 , we scanned the entire crosssectional area of HVC and counted all cells within the border of HVC that showed positive cytosolic labeling that was higher than background. The observer was blind to treatment.

Statistics. We used a two-tailed paired $t$ test to compare ipsilateral with contralateral attributes, a power analysis on paired $t$ tests to assess the likelihood of false negatives, and two-way ANOVAs and $t$ tests to compare the regression of contralateral HVC attributes with previously published data (Thompson et al., 2007). The $\alpha$ level for all tests was 0.05 .

\section{Results}

We measured the volume of song nuclei from Nissl-stained sections. Given that the projection from HVC to RA is unilateral and bilaterally symmetrical, unilateral infusion of caspase inhibitors leaves the untreated contralateral hemisphere to serve as a within-animal control. We therefore compared measurements ipsilateral to the infusion with the contralateral hemisphere with paired $t$ tests ( $\alpha=0.05$, two-tailed). Caspase inhibitor infusion somewhat reduced the regression of HVC volume $1 \mathrm{~d}$ after T withdrawal and photoshift, but this reduction was not statistically significant $(p=0.100)$. We found that infusion of caspase inhibitors did, however, significantly rescue ipsilateral HVC volume $3 \mathrm{~d}(p=0.039)$ and $7 \mathrm{~d}(p=0.003)$ after T withdrawal and photoshift (Fig. $2 A$ ). Infusion of a caspase inhibitor negative control for $7 \mathrm{~d}$ did not preserve HVC volume ( $p=0.321)$ (Fig. $2 A$ ).

We measured HVC neuronal attributes from Nissl-stained sections using a random, systematic counting scheme. Caspase inhibitor infusion significantly preserved the area of the soma of HVC neurons $7 \mathrm{~d}(p=0.021)$ after T withdrawal and photoshift (Fig. $2 B$ ). Caspase inhibitor infusion somewhat preserved HVC soma area 1 and $3 \mathrm{~d}$ after $\mathrm{T}$ withdrawal and photoshift, but this reduction was not statistically significant $(p=0.078$ and 0.090 , respectively) (Fig. $2 \mathrm{~B}$ ). The regression of HVC volume attributable to the withdrawal of T and shift to SD is initially mediated by an increase in neuron density over the first few days, followed by a subsequent decrease in neuron number (Thompson et al., $2007)$. Consistent with these observations, infusion reduced the increase in HVC neuron density at $1 \mathrm{~d}(p=0.018)$ and $3 \mathrm{~d}(p=$ 0.033) (Fig. 2C). At $7 \mathrm{~d}$, neither infusion of caspase inhibitors nor negative control had any effect on HVC neuron density ( $p=$ 0.511 and 0.879 , respectively) (Fig. $2 C$ ). Caspase inhibitor infusion protected HVC neurons from loss $3 \mathrm{~d}(p=0.040)$ and $7 \mathrm{~d}$ $(p=0.005)$ but had no effect $1 \mathrm{~d}(p=0.325)$ after manipulation (Fig. 2D). Infusion of negative control did not prevent HVC neuron loss $7 \mathrm{~d}$ after manipulation $(p=0.081)$.

Caspase inhibitor infusion near HVC protected some, but not all, neuronal attributes of ipsilateral RA, an efferent target of HVC. Infusion of caspase inhibitors significantly preserved RA soma area $7 \mathrm{~d}(p=0.030)$ but not $1 \mathrm{~d}(p=0.464)$ and $3 \mathrm{~d}(p=$ 0.499 ) after $T$ withdrawal and photoshift (Fig. 3). Infusion of caspase inhibitor negative control did not prevent the regression of RA soma area ( $p=0.597)$. Infusion of caspase inhibitors had no effect on nucleus volume of RA, RA neuron density, or neuron number at any time point examined (supplemental Fig. 1, available at www.jneurosci.org as supplemental material). 
We measured the volume of Area X, an efferent target of HVC neurons, and found that it did not differ across hemispheres in any time point (supplemental Fig. 2, available at www.jneurosci.org as supplemental material).

Caspase inhibitor infusion reduced the incidence of cells positive for activated caspase- $33 \mathrm{~d}$ after T withdrawal and photoshift (Fig. 4A). We found that caspase inhibitor infusion reduced the density $(p=0.010)$ and number $(p=0.040)$ of activated caspase-3-positive cells in the ipsilateral HVC (Fig. 4B,C). In addition, caspase inhibitor infusion reduced the number of activated caspase-3-positive cells per $1000 \mathrm{HVC}$ neurons $(p=0.012$, data not shown). We processed tissue from $1 \mathrm{~d}$ animals for activated caspase- 3 and found relatively little labeling; histology from one bird did not allow us to analyze the data quantitatively. Also, we had not yet optimized immunostaining for activated capase- 3 when we processed tissue from $7 \mathrm{~d}$ animals.

We performed power analysis on some marginally significant results to determine the likelihood that the outcome may be explained by insufficient power. There were three results that were marginally significant $(0.05 \leq p$ value $\leq 0.1)$ and showed differences across hemispheres $>10 \%$; we use this level as a criterion for assessing whether a difference across hemispheres may be meaningful. Soma area was 12.9 and $15.0 \%$ larger in the ipsilateral HVC in the 1 and 3 day animals, respectively. The $p$ values for HVC soma area in the 1 and $3 \mathrm{~d}$ animals were 0.078 and 0.09 with power of 0.422 and 0.345 , however. Ipsilateral HVC volume was $23 \%$ larger than the contralateral HVC in the $1 \mathrm{~d}$ animals, and the $p$ value was 0.10 with power of 0.34 . These marginal results may be attributable to several factors, including relatively low $N$ and high variability across animals. These marginal results are not solely attributable to low $N$, however. HVC neuron density was significantly different across hemispheres in the $1 \mathrm{~d}$ group $(p=0.018)$, and the power was 0.933 . This shows that statistical differences with sufficiently high power can be obtained from paired $t$ tests with only three animals. Nevertheless, the three results with marginal results discussed above should be interpreted cautiously.

We performed two types of statistical analysis to determine whether the regression in the contralateral HVC that we report here is comparable with previously published results (Thompson et al., 2007): two-way ANOVAs comparing the current dataset with those from Thompson et al. (2007) using two time points from both studies, and $t$ tests comparing LD $+\mathrm{T}$ data from Thompson et al. (2007) with $7 \mathrm{~d}$ data from the current study. In summary, results from two-way ANOVAs and $t$ tests showed that contralateral neuronal attributes in the current study regressed following a similar time course to that reported in Thompson et al. (2007). Details of these analyses can be found in the supplemental materials.

We measured circulating levels of $\mathrm{T}$ of each bird 7-14 d after the initiation of $\mathrm{LD}+\mathrm{T}$ and again when the animals were killed.
Circulating T levels for all birds used in the study while under LD conditions $(12.78 \pm 1.03 \mathrm{ng} / \mathrm{ml}$; mean \pm SEM $)$ were comparable with those seen in breeding Gambel's white-crowned sparrows in the wild (Wingfield and Farner, 1978). Circulating levels of T when the animals were killed $(0.62 \pm 0.15 \mathrm{ng} / \mathrm{ml})$ were below 1 $\mathrm{ng} / \mathrm{ml}$, which, together with visual verification of the absence of testes at the time of death, confirmed successful withdrawal of circulating $\mathrm{T}$ and transition to nonbreeding hormonal state. The intra-assay coefficient of variation was $\sim 5 \%$, and the interassay coefficient of variation was $12 \%$. We did not collect enough plasma from one animal when the animals was killed and had to exclude it from hormone analysis. Visual inspection after the animals were killed confirmed that this animal had no testes, however, and was therefore included in the study.

\section{Discussion}

Our results show that the rapid regression of HVC caused by T withdrawal and photoshift is dependent on the activity of caspases. The infusion of a mixture of caspase inhibitors near HVC in vivo results in the near-complete preservation of ipsilateral HVC after the withdrawal of circulating $\mathrm{T}$ and transition to $\mathrm{SD}$. The volume of HVC normally regresses within $12 \mathrm{~h}$ after the withdrawal of $\mathrm{T}$; continuous infusion of caspase inhibitors prevents this regression for nearly $7 \mathrm{~d}$. Conversely, infusion of a negative control for caspase inhibitors did not preserve the ipsilateral HVC, which demonstrates that the protective effects of caspase inhibitor infusion in HVC are attributable to the action of 


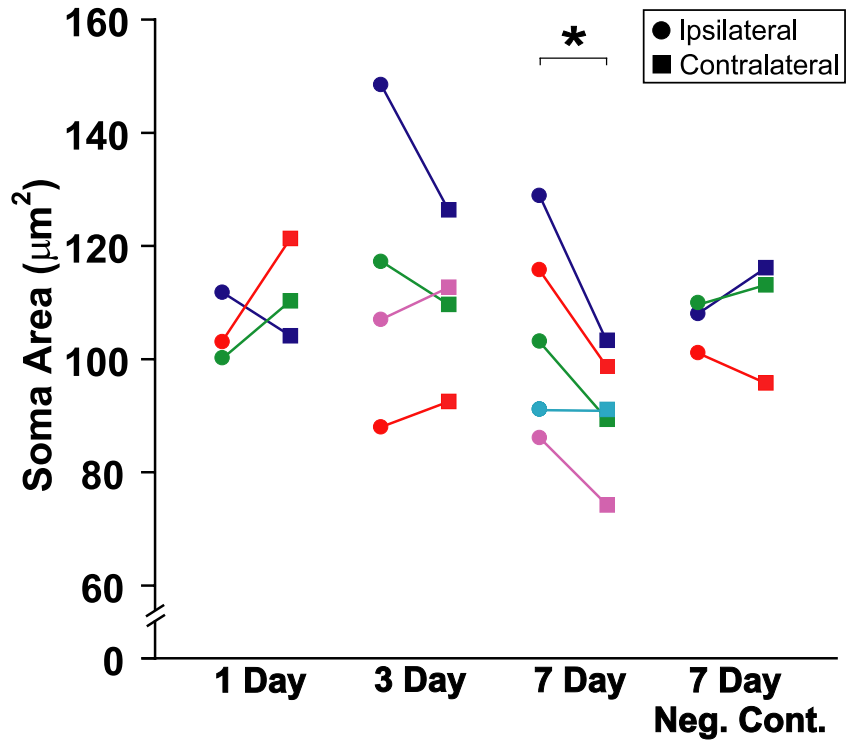

Figure 3. In vivo infusion of caspase inhibitors near HVC significantly preserved soma area of ipsilateral RA neurons $7 \mathrm{~d}$ after the transition to nonbreeding conditions. Each animal within each group is represented by a distinct color. Circles represent measurements taken in ipsilateral $\mathrm{RA}$; squares represent measurements taken in contralateral $\mathrm{RA}^{*} p \leq 0.05$, significant difference across hemispheres (pairwise $t$ test).

caspase inhibitors and not attributable to some nonspecific effect of the vehicle or the surgical implantation of the cannula. Caspase inhibitors had protective effects on every neuronal attribute of HVC that we measured, including a significant increase in the survival of HVC neurons. In addition, we showed that there was a high number of activated caspase-3-positive cells in the contralateral HVC $3 \mathrm{~d}$ after the transition to nonbreeding conditions and that in vivo infusion of caspase inhibitors reduced the activation of caspase- 3 in ipsilateral HVC. Together, these results show that activation of caspases is necessary for the seasonal regression of HVC.

The withdrawal of circulating $\mathrm{T}$ from adult male whitecrowned sparrows induces a rapid regression of HVC volume to nonbreeding size within $12 \mathrm{~h}$, and this initial decline is attributable to a substantial increase in neuron density (Thompson et al., 2007). This increase in neuron density reflects a decrease in extracellular space and strongly suggests the occurrence of significant atrophy of axonal and/or dendritic arbors within the neuropil of HVC. There is precedent for caspase-dependent modification of dendritic and axonal arbors; for instance, the activation of caspases is necessary for the pruning of dendrites of sensory neurons during the metamorphosis of Drosophila melanogaster (Williams et al., 2006). The activation of caspases can regulate synaptic plasticity within neurons without the activation of programmed cell death pathways that lead to apoptosis. In zebra finch auditory forebrain, there is a brief increase of caspase- 3 activation in dendritic spines within minutes of exposure to novel song with no subsequent neuron loss (Huesmann and Clayton, 2006). Our results suggest that increases in HVC neuron density, if driven by degenerating neuropil, may be caspase dependent given that in vivo infusion of caspase inhibitor prevented the increase in neuron density 1 and $3 \mathrm{~d}$ after transition to nonbreeding conditions. Our data, however, do not necessarily indicate that caspase inhibitors solely affect dendritic and/or axonal pruning, despite the fact that caspase inhibitors preserve ipsilateral HVC neuron density. Instead, the initial increase in HVC neuron density after the transition to nonbreeding condi-

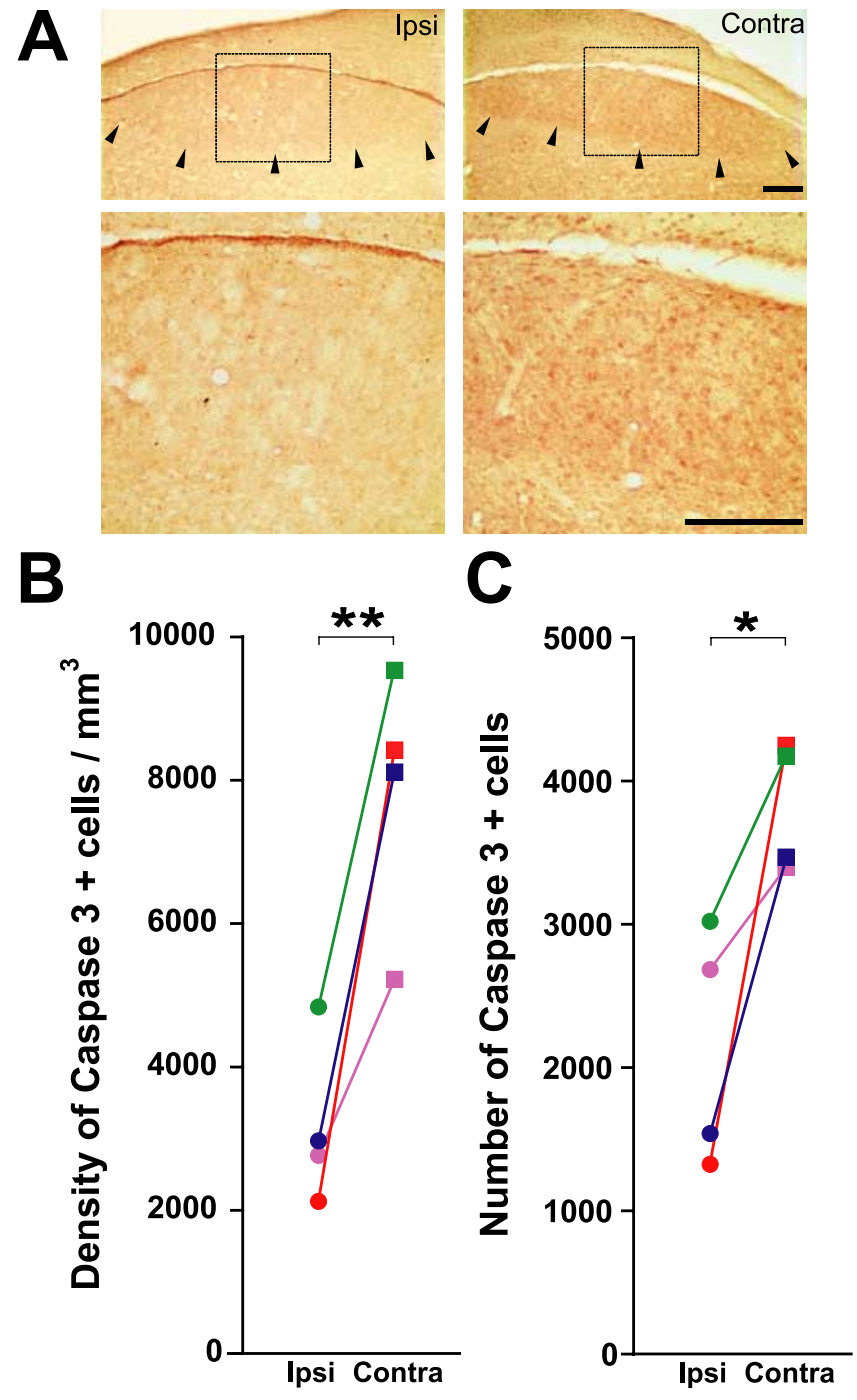

Figure 4. In vivo infusion of caspase inhibitors near HVC significantly reduced the activation of capsase-3 in ipsilateral HVC 3 d after the transition from breeding to nonbreeding conditions. $\boldsymbol{A}$, Examples of immunohistochemistry for activated caspase- 3 in one section taken from a $3 \mathrm{~d}$ bird. $\boldsymbol{B}$, Caspase inhibitors significantly reduced the density of activated caspase-3-positive cells in ipsilateral HVC. C, Caspase inhibitors significantly reduced the number of activated caspase3-positive cells in ipsilateral HVC. Each animal is represented by a distinct color. ${ }^{*} p \leq 0.05$, ${ }^{* *} p \leq 0.01$, significant differences across hemispheres (pairwise $t$ test). Scale bars, $100 \mu \mathrm{m}$.

tions may be a result of the retraction of dendrites and axons of HVC neurons that have already initiated programmed cell death and eventually die days later, whereas the arbors of HVC neurons that survive may not undergo degeneration. In addition, changes in HVC neuron density may be the result of changes within nonneuronal cells such as glia or endothelial tissue, both of which are sensitive to changes in circulating levels of $\mathrm{T}$ (Louissaint et al., 2002; Satriotomo et al., 2004). Future studies that specifically examine the underlying mechanisms that mediate rapid degeneration of HVC neuropil, including dendritic and/or axonal pruning or regression of non-neuronal cells within the hours after $\mathrm{T}$ withdrawal, may reconcile this issue.

Neuron number in HVC decreases by $26 \%$ within $7 \mathrm{~d}$ after the transition to nonbreeding conditions (Thompson et al., 2007). In vivo infusion of caspase inhibitors, however, provides complete protection of HVC neurons under these conditions; on average, ipsilateral HVC neuron number was $28 \%$ greater than contralateral HVC at $7 \mathrm{~d}$. Caspase inhibitors also preserved HVC soma 
area for at least $7 \mathrm{~d}$ after $\mathrm{T}$ withdrawal and photoshift; average ipsilateral HVC soma area was 13\% larger than contralateral, comparable with measurements seen in birds killed under breeding conditions (Thompson et al., 2007). In addition, two-way ANOVAs and $t$ tests show that the regression of the contralateral HVC was comparable with previously published results (Thompson et al., 2007). These results strongly suggest that infusion of caspase inhibitor provides full protection for several neuronal attributes that otherwise are compromised under seasonal-like transition to nonbreeding conditions.

Although our results are the first demonstration that in vivo administration of caspase inhibitors can ameliorate neurodegeneration attributable to the withdrawal of circulating sex steroids, caspase inhibitors have been used successfully to rescue brain areas affected by neurodegeneration attributable to other causes. Ischemia and status epilepticus induce programmed cell death and subsequent neuron loss in the mammalian hippocampus and cortex, and in vivo administration of caspase inhibitors reduces this process (Himi et al., 1998; Mattson et al., 2000; Ekdahl et al., 2002; Reshef et al., 2007). Caspase inhibitors also increase the short-term survival of new neurons incorporated into the hippocampus (Ekdahl et al., 2001). Indeed, the balance of incorporation and death of neurons in the dentate gyrus can be affected by acute injections of caspase inhibitors in rats (Dupret et al., 2007). Caspase inhibitors have been shown to influence of the consolidation of new memories in mammals (Dupret et al., 2007) and birds (Huesmann and Clayton, 2006). Given these effects, caspase inhibitors may prove to have clinical application in ameliorating neurodegenerative processes in humans (Ray, 2006).

Although it has not yet been conclusively shown in whitecrowned sparrows, studies in zebra finches suggest that the only HVC neurons that are replaced in adults are those that project to RA (Scotto-Lomassese et al., 2007). Neurons rescued with caspase inhibitors in sparrows after the transition to nonbreeding conditions may also be mostly neurons that project to RA. Our results show that in vivo infusion of caspase inhibitors near HVC reduced the regression of average soma area in ipsilateral RA $7 \mathrm{~d}$ after the transition to nonbreeding conditions. The observation of a trans-synaptic trophic influence of HVC on RA neurons is consistent with previous results. Lesions of HVC block the growth and maintenance of RA in sparrows exposed to breeding conditions (Brenowitz and Lent, 2001), demonstrating that some characteristic of HVC, possibly increased release of trophic factors and/or enhanced electrophysiological activity of RAprojecting HVC neurons, is necessary for the growth of RA (A. M. Wissman and E. A. Brenowitz, unpublished results) (Meitzen et al., 2007). This transsynaptic rescue of RA is not complete, however; infusion of caspase inhibitors near HVC preserved ipsilateral RA soma area but had no effect on RA neuron density. If caspase inhibitors were to have an effect on RA neuron density, we would expect to see it here because density is significantly increased by $2 \mathrm{~d}$ after the transition to nonbreeding conditions and continues to increase thereafter (Thompson et al., 2007). There are several possible explanations for these observations. First, we only used one dose in our study; preserving RA neuron density, which likely reflects changes in dendritic arborization, may require a higher concentration of caspase inhibitors. Second, RA soma area and neuron density may be differentially regulated, and caspase inhibitors may not be sufficient to prevent changes in dendritic arborization and/or axonal terminal fields that likely determine RA neuron density. In addition, there is precedent for dissociation of dendritic changes and soma size; Deitch and Rubel (1984) found that deafferentation of nucleus laminaris neurons induced dendritic retraction with no change in soma size, further suggesting that soma area and dendritic arborization may be differentially regulated. Last, the rapid transition to nonbreeding conditions initiates a cascade of events that leads to the activation of caspases and ultimately neurodegeneration. The point at which caspase inhibitors exert their influence is relatively far along the causal chain of events that mediate programmed cell death (Danial and Korsmeyer, 2004). Thus, caspase inhibitors may not provide the full complement of support for compromised HVC neurons that are necessary for transsynaptic influence over RA neurons. Nevertheless, our results suggest that a population of HVC neurons that would otherwise be eliminated via programmed cell death pathways in the days after the transition to nonbreeding conditions are rescued with caspase inhibitors and maintain enough integrity to have some transsynaptic influence on the morphology of efferent RA neurons.

Although photoperiod and song rate have some influence over morphological change within the song control system (Smith et al., 1997; Bentley et al., 1999; Sartor and Ball, 2005), T and/or its metabolites play a much more direct and significant role (Smith et al., 1997). As noted above, T acts locally within HVC to induce the growth of ipsilateral song control system nuclei (Brenowitz and Lent, 2002), including a significant increase in HVC neuron number. Thus, it seems that, under breeding conditions, elevated levels of circulating $\mathrm{T}$ promotes the survival of HVC neurons, which in turn induces the growth of efferent nuclei, and that the rapid withdrawal of $\mathrm{T}$ initiates a rapid caspase-dependent degeneration of the song control system. These observations strongly suggest that $\mathrm{T}$ and/or its metabolites play a neuroprotective role in HVC not unlike the hormonemediated neuroprotection that is seen in several in vivo animal models of neuronal injury (Ramsden et al., 2003; Pike et al., 2006). In mammals, $T$ and $E_{2}$ upregulate the expression of antiapoptotic genes (Singer et al., 1998; Dubal et al., 1999; Pike, 1999; Stoltzner et al., 2001; Zup and Forger, 2002; Chiueh et al., 2003; Wu et al., 2005). In zebra finches, neuronal injury is accompanied by an increase in expression of aromatase, an enzyme that converts $\mathrm{T}$ to $\mathrm{E}_{2}$ (Peterson et al., 2001), and inhibition of aromatase increases apoptosis near the injury (Saldanha et al., 2005). Seasonal-like rapid regression of the song control system serves as an excellent model to further elucidate the molecular mechanisms that underlie hormone-mediated neurodegeneration.

\section{References}

Bentley GE, Van't Hof TJ, Ball GF (1999) Seasonal neuroplasticity in the songbird telencephalon: a role for melatonin. Proc Natl Acad Sci U S A 96:4674-4679.

Breedlove SM, Arnold AP (1981) Sexually dimorphic motor nucleus in the rat lumbar spinal cord: response to adult hormone manipulation, absence in androgen-insensitive rats. Brain Res 225:297-307.

Brenowitz EA, Lent K (2001) Afferent input is necessary for seasonal growth and maintenance of adult avian song control circuits. J Neurosci 21:2320-2329.

Brenowitz EA, Lent K (2002) Act locally and think globally: intracerebral testosterone implants induce seasonal-like growth of adult avian song control circuits. Proc Natl Acad Sci U S A 99:12421-12426.

Chiueh C, Lee S, Andoh T, Murphy D (2003) Induction of antioxidative and antiapoptotic thioredoxin supports neuroprotective hypothesis of estrogen. Endocrine 21:27-31.

Coggeshall RE, Lekan HA (1996) Methods for determining numbers of cells and synapses: a case for more uniform standards of review. J Comp Neurol 364:6-15.

Commins D, Yahr P (1984) Adult testosterone levels influence the morphology of a sexually dimorphic area in the Mongolian gerbil brain. J Comp Neurol 224:132-140.

Cooke BM, Tabibnia G, Breedlove SM (1999) A brain sexual dimorphism 
controlled by adult circulating androgens. Proc Natl Acad Sci U S A 96:7538-7540.

Danial NN, Korsmeyer SJ (2004) Cell death: critical control points. Cell 116:205-219.

Deitch JS, Rubel EW (1984) Afferent influences on brain stem auditory nuclei of the chicken: time course and specificity of dendritic atrophy following deafferentation. J Comp Neurol 229:66-79.

Dubal DB, Shughrue PJ, Wilson ME, Merchenthaler I, Wise PM (1999) Estradiol modulates bcl-2 in cerebral ischemia: a potential role for estrogen receptors. J Neurosci 19:6385-6393.

Dupret D, Fabre A, Döbrössy MD, Panatier A, Rodríguez JJ, Lamarque SP, Lemaire V, Oliet SHR, Piazza P-V, Abrous DN (2007) Spatial learning depends on both the addition and removal of new hippocampal neurons. PLoS Biol 5:e214.

Ekdahl CT, Mohapel P, Elmer E, Lindvall O (2001) Caspase inhibitors increase short-term survival of progenitor-cell progeny in the adult rat dentate gyrus following status epilepticus. Eur J Neurosci 14:937-945.

Ekdahl CT, Mohapel P, Weber E, Bahr B, Blomgren K, Lindvall O (2002) Caspase-mediated death of newly formed neurons in the adult rat dentate gyrus following status epilepticus. Eur J Neurosci 16:1463-1471.

Garcia-Segura LM, Azcoitia I, DonCarlos LL (2001) Neuroprotection by estradiol. Prog Neurobiol 63:29-60.

Himi T, Ishizaki Y, Murota SI (1998) A caspase inhibitor blocks ischaemia induced delayed neuronal death in the gerbil. Eur J Neurosci 10:777-781.

Huesmann GR, Clayton DF (2006) Dynamic role of postsynaptic caspase-3 and BIRC4 in zebra finch song-response habituation. Neuron 52:1061-1072.

Iela L, D’Aniello B, Di Meglio M, Rastogi RK (1994) Influence of gonadectomy and steroid hormone replacement therapy on the gonadotropinreleasing hormone neuronal system in the anterior preoptic area of the frog (Rana esculenta) brain. Gen Comp Endocrinol 95:422-431.

Kumar S (2006) Caspase function in programmed cell death. Cell Death Differ 14:32-43.

Louissaint A Jr, Rao S, Leventhal C, Goldman SA (2002) Coordinated interaction of neurogenesis and angiogenesis in the adult songbird brain. Neuron 34:945-960.

Mattson MP (2000) Apoptosis in neurodegenerative disorders. Nat Rev Med Cell Biol 1:120-130.

Mattson MP, Culmsee C, Yu ZF (2000) Apoptotic and antiapoptotic mechanisms in stroke. Cell Tissue Res 301:173-187.

Meitzen J, Moore IT, Lent K, Brenowitz EA, Perkel DJ (2007) Steroid hormones act transsynaptically within the forebrain to regulate neuronal phenotype and song stereotypy. J Neurosci 27:12045-12057.

Nauta WJH, Ebbesson SOE (1970) National Institute of Neurological Diseases and Stroke, University of Puerto Rico (Râio Piedras Campus) contemporary research methods in neuroanatomy. New York: Springer.

Okouchi M, Ekshyyan O, Maracine M, Aw TY (2007) Neuronal apoptosis in neurodegeneration. Antioxid Redox Signal 9:1059-1096.

Panzica GC, Viglietti-Panzica C, Calacagni M, Anselmetti GC, Schumacher M, Balthazart J (1987) Sexual differentiation and hormonal control of the sexually dimorphic medial preoptic nucleus in the quail. Brain Res 416:59-68.

Peterson RS, Saldanha CJ, Schlinger BA (2001) Rapid upregulation of aromatase mRNA and protein following neural injury in the zebra finch (Taeniopygia guttata). J Neuroendocrinol 13:317-323.

Pike CJ (1999) Estrogen modulates neuronal Bcl-xL expression and betaamyloid-induced apoptosis: relevance to Alzheimer's disease. J Neurochem 72:1552-1563.

Pike CJ, Rosario ER, Nguyen TV (2006) Androgens, aging, and Alzheimer's disease. Endocrine 29:233-241.

Ramsden M, Shin TM, Pike CJ (2003) Androgens modulate neuronal vulnerability to kainate lesion. Neuroscience 122:573-578.

Ray SK (2006) Currently evaluated calpain and caspase inhibitors for neu- roprotection in experimental brain ischemia. Curr Med Chem 13:3425-3440.

Reshef A, Shirvan A, Grimberg H, Levin G, Cohen A, Mayk A, Kidron D, Djaldetti R, Melamed E, Ziv I (2007) Novel molecular imaging of cell death in experimental cerebral stroke. Brain Res 1144:156-164.

Saldanha CJ, Rohmann KN, Coomaralingam L, Wynne RD (2005) Estrogen provision by reactive glia decreases apoptosis in the zebra finch (Taeniopygia guttata). J Neurobiol 64:192-201.

Sartor JJ, Ball GF (2005) Social suppression of song is associated with a reduction in volume of a song-control nucleus in European starlings (Sturnus vulgaris). Behav Neurosci 119:233-244.

Satriotomo I, Miki T, Gonzalez D, Matsumoto Y, Li H-P, Gu H, Takeuchi Y (2004) Excessive testosterone treatment and castration induce reactive astrocytes and fos immunoreactivity in suprachiasmatic nucleus of mice. Brain Res 1020:130-139.

Scotto-Lomassese S, Rochefort C, Nshdejan A, ScharffC (2007) HVC interneurons are not renewed in adult male zebra finches. Eur J Neurosci 25:1663-1668.

Singer CA, Rogers KL, Dorsa DM (1998) Modulation of Bcl-2 expression: a potential component of estrogen protection in NT2 neurons. Neuroreport 9:2565-2568.

Smith GT, Brenowitz EA, Wingfield JC (1997) Roles of photoperiod and testosterone in seasonal plasticity of the avian song control system. J Neurobiol 32:426-442.

Soma KK, Francis RC, Wingfield JC, Fernald RD (1996) Androgen regulation of hypothalamic neurons containing gonadotropin-releasing hormone in a cichlid fish: integration with social cues. Hormones Behav $30: 216-226$.

Stoltzner SE, Berchtold NC, Cotman CW, Pike CJ (2001) Estrogen regulates bcl-x expression in rat hippocampus. Neuroreport 12:2797-2800.

Thompson CK, Brenowitz EA (2005) Seasonal change in neuron size and spacing but not neuronal recruitment in a basal ganglia nucleus in the avian song control system. J Comp Neurol 481:276-283.

Thompson CK, Bentley GE, Brenowitz EA (2007) Rapid seasonal-like regression of the adult avian song control system. Proc Natl Acad Sci U S A 104:15520-15525.

Tramontin AD, Smith GT, Breuner CW, Brenowitz EA (1998) Seasonal plasticity and sexual dimorphism in the avian song control system: stereological measurement of neuron density and number. J Comp Neurol 396:186-192.

Tramontin AD, Hartman VN, Brenowitz EA (2000) Breeding conditions induce rapid and sequential growth in adult avian song control circuits: a model of seasonal plasticity in the brain. J Neurosci 20:854-861.

Veiga S, Melcangi RC, Doncarlos LL, Garcia-Segura LM, Azcoitia I (2004) Sex hormones and brain aging. Exp Gerontol 39:1623-1631.

Wade J, Huang JM, Crews D (1993) Hormonal control of sex differences in the brain, behavior and accessory sex structures of whiptail lizards (Cnemidophorus species). J Neuroendocrinol 5:81-93.

West MJ (1993) New stereological methods for counting neurons. Neurobiol Aging 14:275-285.

Williams DW, Kondo S, Krzyzanowska A, Hiromi Y, Truman JW (2006) Local caspase activity directs engulfment of dendrites during pruning. Nat Neurosci 9:1234-1236.

Wingfield JC, Farner DS (1978) The annual cycle of plasma irLH and steroid hormones in feral populations of the white-crowned sparrow, Zonotrichia leucophrys gambelii. Biol Reprod 19:1046-1056.

Wu TW, Wang JM, Chen S, Brinton RD (2005) 17Beta-estradiol induced $\mathrm{Ca}^{2+}$ influx via L-type calcium channels activates the Src/ERK/cyclicAMP response element binding protein signal pathway and BCL-2 expression in rat hippocampal neurons: a potential initiation mechanism for estrogen-induced neuroprotection. Neuroscience 135:59-72.

Zup SL, Forger NG (2002) Testosterone regulates BCL-2 immunoreactivity in a sexually dimorphic motor pool of adult rats. Brain Res 950:312-316. 